\title{
Comparecimento eleitoral na América Latina: uma análise multinível comparada
}

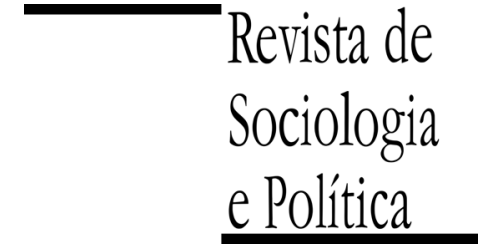

DOI 10.1590/1678-987315235406

\author{
Ednaldo Aparecido Ribeiro, Julian Borba \\ e Rafael da Silva
}

Resumo

Pela sua centralidade no regime democrático, a participação eleitoral é objeto privilegiado de muitos politólogos. Em geral, os estudos se voltaram para a realidade dos países desenvolvidos, abordando, entre outros temas, o comparecimento eleitoral e seus determinantes. Poucas são as pesquisas que contemplam, pelo menos de forma consistente, os regimes democráticos de terceira onda, especialmente os latino-americanos. Procurando contribuir para suprir essa lacuna, o presente artigo procurou mapear os determinantes do comparecimento eleitoral na América Latina, rompendo com a dicotomia macro versus micro, integrando-as em um único modelo analítico. Foram utilizados dados do Latinobarômetro, em sua rodada de 2009, dos quais extraímos as variáveis de nível micro (individual) e uma base de dados com informações macro dos países onde vivem os eleitores. Essas últimas medidas sintetizam a situação da economia dos países, características do seus sistemas eleitorais e a situação das liberdades políticas e individuais, entre outras. Os dados foram combinados em um modelo de regressão logística multinível com o uso do software HLM 6.8. A dimensão ecológica se mostrou importante, sendo que o aumento da população urbana implica o aumento das chances do eleitor comparecer, enquanto que a elevação do PIB implica redução nessa probabilidade. Do ponto de vista da configuração do legislativo, ser bicameral reduz as chances de comparecimento dos eleitores às urnas. Além disso, a obrigatoriedade do voto eleva expressivamente o comparecimento eleitoral. Quanto às variáveis individuais, o aumento dos anos de vida é acompanhado pelo aumento da participação eleitoral, assim como a escolaridade. Da mesma forma, ser favorável a democracia promove a propensão a participar do pleito, bem como considerar que as eleições ocorrem de forma limpa e transparente. $\mathrm{O}$ artigo contribui para o debate ao focalizar as eleições latino-americanas, já que estudos desse tipo têm sido conduzidos apenas nas democracias consolidadas. Sua relevância é ainda reforçada em razão da identificação de algumas importantes discrepâncias em relação aos resultados normalmente encontrados nesses contextos de longa tradição democrática, como os efeitos negativos do PIB e da efetividade governamental. Por fim, o que os dados indicam é que o comparecimento eleitoral na América Latina é a "voz" dos cidadãos portadores de maiores recursos, que valorizam a democracia e suas instituições, mas que estão insatisfeitos com a economia e que vivem em contextos de baixa efetividade na atuação dos governos.

Palavras-chave: comparecimento eleitoral; condicionantes estruturais; determinantes individuais; analise multinível; América Latina.

Recebido em 21 de Março de 2014. Aprovado em 19 de Junho de 2014.

\section{Introdução ${ }^{1}$}

${ }^{1}$ Agradecemos aos pareceristas anônimos da Revista de Sociologia e Política por seus comentários.

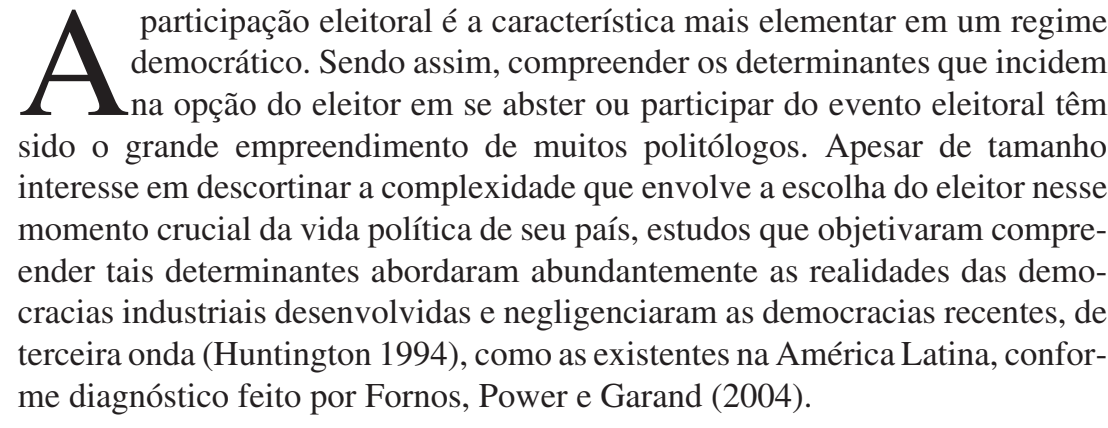

Rev. Sociol. Polit., v. 23, n. 54, p. 91-108, jun. 2015 
${ }^{2}$ Os 18 países são: Argentina, Bolívia, Brasil, Chile, Colômbia, Costa Rica, El Salvador, Equador, Guatemala, Honduras, México, Nicarágua, Panamá, Paraguai, Peru, República Dominicana, Uruguai e Venezuela.

Dessa forma, suprindo essa carência, realiza-se um estudo comparado dos determinantes do comparecimento eleitoral na América Latina. Procura-se romper com a dicotomia presente nos estudos tradicionais sobre o tema, os quais têm mapeado isoladamente os determinantes individuais e estruturais que incidem no comportamento eleitoral. Tais estudos elencaram um conjunto de variáveis centrais situadas em um dos dois níveis de análise, para explicar o fenômeno. Em geral, ao nível individual têm-se variáveis como: educação, renda, estado civil, crenças e valores que os cidadãos nutrem para com o regime democrático, entre outras. No nível estrutural tem-se variáveis como: Produto Interno Bruto (PIB) e variáveis que traduzem a situação da economia dos países, características do sistema eleitoral e situação das liberdades políticas e individuais, entre outras.

Porém, com raras exceções (Nevitte et al., 2000), esses estudos careceram de uma tentativa de integração destes dois níveis de análise em um modelo analítico único. Assim, é nesse ponto que reside outra contribuição deste trabalho: integrar, em um único modelo, variáveis cujos níveis analíticos são distintos, porém muito importantes no que diz respeito aos determinantes do comparecimento eleitoral. A análise a que nos referimos é chamada de "multinível" e integra variáveis coletadas em dois planos: as individuais, a partir de survey (rodada de 2009 do Latinobarómetro), e as macroestruturais, cuja unidade de coleta são os 18 países latino-americanos, incluídos na referida rodada do Latinobarómetro $^{2}$, e que traduzem algumas características elementares das realidades socioeconômicas e políticas de cada nação envolvida no estudo.

Para cumprir com esses objetivos, o trabalho estrutura-se da seguinte forma: a próxima seção faz uma breve revisão da literatura sobre comparecimento eleitoral, evidenciando algumas das principais teorias sobre o assunto. $\mathrm{Na}$ sequência, apresentamos as considerações metodológicas de nosso modelo de análise e a justificativa da escolha das variáveis inseridas nele. A quarta seção discute os resultados obtidos com o modelo e, por fim, a conclusão destaca os principais aspectos evidenciados por este estudo empírico.

\section{Comparecimento eleitoral}

\footnotetext{
${ }^{3}$ Dentre os países incluídos na análise, apresentam obrigatoriedade Argentina, Bolívia, Brasil, Chile, Costa Rica, Equador, Guatemala, Honduras, México, Panamá, Paraguai, Peru, República Dominicana e Uruguai.
}

\footnotetext{
${ }^{4}$ Quanto mais próximo do dia da eleição, maior é a propensão do eleitor em externar intenção de comparecer às urnas, significa que quanto mais próximo o pleito, mais relevante este se
}

O quadro geral da literatura sobre comparecimento eleitoral se caracteriza pelo grande volume de estudos sobre seus determinantes nas democracias industriais avançadas e que não adotam formas de "compulsoriedade" como encontradas no Brasil e em muitos países latino-americanos. Dessa forma, realidades como a nossa, onde a obrigatoriedade existe, foram negligenciadas ${ }^{3}$. Nos parágrafos seguintes nos deteremos sobre a apresentação da literatura desenvolvida na última década sobre comparecimento eleitoral, abordando, num primeiro momento, os estudos direcionados às democracias avançadas, $\mathrm{e}$ em seguida, os poucos trabalhos sobre a América Latina.

Geys (2006), em Explaining Voter Turnout: A Review of Aggregate-Level Research, realizou uma sistematização de diversos estudos empíricos em nível agregado e aglutinou as variáveis explicativas mais recorrentes. Primeiramente, o autor apresenta um conjunto de variáveis socioeconômicas: tamanho da população, concentração (rural/urbano) e estabilidade populacional. O segundo conjunto de variáveis é de ordem política: gastos com campanhas, fragmentação política (número de partidos disputando os cargos eletivos) e proximidade das eleições ${ }^{4}$, e um último bloco de ordem institucional: sistema eleitoral, voto obrigatório e simultaneidade de cargos em disputa.

É importante destacar que, como se trata de um exercício de meta-análise sobre um volume considerável de publicações (60 livros ou artigos) sobre o assunto, a base empírica para as conclusões é bastante variada. Em alguns casos 
torna ao eleitor a partir do cálculo que este faz sobre a probabilidade de afetar o resultado eleitoral (Geys 2006, p. 646). os dados se referem à eleições distritais e municipais de países e em outros envolvem unidades nacionais.

As principais conclusões dessa revisão indicam que o comparecimento é maior em unidades nacionais com populações menores e também quando a data das eleições é mais próxima do momento da coleta dos dados sobre a intenção de comparecer. Diferentemente, a concentração e a homogeneidade populacional não se apresentaram como preditores relevantes nos estudos consultados. Também apontam que o gasto de campanha exerce afeito positivo, mas alertam que os mecanismos através dos quais esse efeito ocorre não estão ainda claros na literatura. Os resultados mais expressivos, todavia, referem-se às variáveis institucionais, indicando que o comparecimento aumenta com a obrigatoriedade do voto quando os procedimentos de registros de eleitores são fáceis; quando são realizadas eleições simultâneas para distintos cargos e quando são adotados mecanismos de representação proporcional (idem, p. 653).

André Blais (2006), em seu artigo “What Affects Voter Turnout?", propõese a lançar luz para estudos que procurem respostas às seguintes questões: por que o comparecimento eleitoral é maior em alguns países do que em outros? Por que as taxas de comparecimento aumentam ou diminuem ao longo do tempo? Para ajudar a responder tais questões, o autor apresenta um conjunto de variáveis institucionais centrais: obrigatoriedade do voto, sistema eleitoral, uni/bicameralismo, idade mínima para votar e a existência ou não de regras que facilitem o comparecimento, porém, a dificuldade está em como operacionalizar tais variáveis para estudá-las, por exemplo, em perspectiva comparada.

Já o estudo de Denny e Doyle (2008) usa dados longitudinais do National Child Development Study (NCDS) para investigar os determinantes individuais da participação eleitoral em 1997 nas eleições gerais britânicas. Usando medidas de capacidade cognitiva e personalidade, descobre que elas são determinantes significativas da participação eleitoral. Destaca também que o comparecimento eleitoral pode ser influenciado pela inclusão do "interesse na política" nos modelos de análise. Conclui ainda que indivíduos com alta capacidade de compreensão dos fenômenos políticos e uma personalidade agressiva são mais propensos a votar e ter alto interesse na política.

Dettrey e Schwindt-Bayer (2009), em "Voter Turnout in Presidential Democracies" , identificam que certas variações do modelo presidencialista, como a reeleição e dois turnos, impactam positivamente o comparecimento eleitoral. Porém, resgatando outros estudos, salientam que outras instituições ligadas ao contexto político (número de candidatos/partidos, voto obrigatório, Freedom House, entre outros) e também ao ambiente socioeconômico (PIB per capita e seu crescimento) são relevantes e impactam positivamente a participação eleitoral.

Seguindo na esteira dos estudos cujo foco são as democracias industriais avançadas, tem-se o trabalho de Gallego (2010), "Understanding Unequal Turnout: Education and Voting in Comparative Perspective". A autora observa que diferentes níveis educacionais estão relacionados a diferentes taxas de comparecimento eleitoral em países como EUA, República Tcheca e Alemanha. Suas conclusões corroboram os achados de Nevitte et al. (2000) de que alto nível educacional se torna um fator facilitador da ação política, deixando-a menos custosa para o eleitor.

Com relação aos estudos sobre comparecimento eleitoral na América Latina, os estudos são bastante escassos. Essa carência foi diagnosticada por Fornos, Power e Garand (2004) em seu artigo "Explaining Voter Turnout in Latin America, 1980 to 2000": 
6 "Os estudos que originaram essas abordagens teóricas concorrentes dedicaram-se em larga medida às democracias industrializadas, fazendo com que nos indagássemos se seus achados são aplicáveis a países menos desenvolvidos, com regimes democráticos emergentes" (tradução do revisor).

7 Os países contemplados pelo estudo são os mesmos 18 deste trabalho.

${ }^{8}$ Composto pelo Senado e Câmara dos Deputados, que no caso brasileiro formam o Congresso Nacional.

\footnotetext{
9 Mesmo concentrando sua análise nos efeitos em nível individual, Carreras e Angarita (2013) realizam testes empíricos utilizando modelagem hierárquica de dados.
}

"The studies that gave rise to these contending theoretical approaches were largely conducted among the industrialized democracies, leading us to wonder whether their findings are applicable to less developed countries with emerging democratic regimes" ${ }^{\prime}$ (idem, p. 910).

Dessa forma, para entender os determinantes do comparecimento eleitoral na América Latina, os autores o fazem em perspectiva comparada e, com base na literatura, utilizaram variáveis socioeconômicas e políticas, além de fatores institucionais que caracterizam o sistema político dos países, sendo estes a unidade de análise ${ }^{7}$. Os achados indicam que o comparecimento em países latino-americanos é influenciado pelos seguintes fatores institucionais: presença/ausência de legislativo bicameral $^{8}$, voto obrigatório/voluntário e simultaneidade entre eleições legislativa e executiva. O efeito negativo do bicameralismo é interpretado pelos autores como reflexo da maior dificuldade que tal composição gera para a identificação das coalisões de governo e dos resultados legislativos por parte dos eleitores. $\mathrm{O}$ efeito positivo da obrigatoriedade, por razões óbvias, é atribuído à existência de sanções aplicáveis àqueles que deixam de comparecer. O impacto da simultaneidade de eleições para o Executivo e Legislativo, por sua vez, é explicado pela maior intensidade política do evento, em especial no que diz respeito ao maior fluxo de informações que acaba contribuindo para a redução dos custos envolvidos na tomada de decisão dos eleitores, tornando mais provável o comparecimento. A existência das duas eleições no mesmo momento tende a formar um eleitorado mais atento e motivado do que aquele que emerge em contextos eleitorais exclusivos.

No terreno dos fatores políticos mais gerais, identificam impactos consideráveis do tempo de vida do regime e da intensidade das garantias de liberdades políticas (Freedom House). No caso da primeira variável o objetivo do autor foi testar a hipótese de O’Donnell e Schimitter (1986) a respeito da redução crescente da participação política na medida em que os processos democráticos se tornam rotineiros e as altas expectativas existentes nos momentos de transição são frustradas após a democratização. Para isso, engenhosamente utilizaram uma variável que identificava as situações em que a eleição analisada era a primeira do período democrático. Com isso foi possível identificar um impacto expressivo dessa condição, ou seja, o comparecimento é expressivamente maior em contextos de recente democratização, corroborando a hipótese do arrefecimento do potencial participativo sugerido por O’Donnell e Schimitter.

Como principal conclusão geral, Fornos, Power e Garand (2004) afirmam que estudos futuros devem ser guiados por um ecletismo maior em termos de variáveis explicativas do comparecimento eleitoral, usando variáveis institucionais, socioeconômicas e políticas. Da mesma forma sugerem que algumas variáveis possuem um peso explicativo maior, como as institucionais e políticas, quando comparadas com as socioeconômicas, ainda que reconheçam que os testes estatísticos, dada a natureza das variáveis, não foram adequados para corroborar essa posição.

O recente trabalho de Carreras e Angarita (2013) buscou testar a capacidade explicativa de três perspectivas teóricas sobre o comparecimento eleitoral para os países da América Latina. São elas: a teoria dos recursos dos eleitores, as teorias sobre atitudes e motivações e aquelas relacionadas às redes de mobilização. Utilizando dados empíricos do LAPOP para o nível individual e de fontes diversas para o nível contextual, os autores se concentram analiticamente na dimensão individual ${ }^{9}$. Suas conclusões indicam que as variáveis demográficas e aquelas relacionadas às redes de mobilização são as maiores preditoras do comparecimento eleitoral na região, em especial escolaridade (proxy de recurso cognitivo) e idade (experiência política), validando portanto a teoria dos recursos. Sobre as variáveis relacionadas às redes de mobilização, identificam o efeito positivo exercido pelas redes de partido, as associações cívicas e aquelas 
relacionadas ao local de trabalho. Em suas conclusões, dialogam diretamente com o trabalho de Fornos, Power e Garand (2004), que na opinião dos autores subestimou o efeito das variáveis sócio-demográficas para o comparecimento eleitoral na região.

Carreras e Irepoglu (2013), também utilizando dados do Lapop (relativos ao ano de 2010), analisam a relação entre confiança política e comparecimento eleitoral na região. Concentrando-se nas dimensões individual e contextual, identificam que o efeito do sentimento de confiança nas eleições é mediado pelo contexto, de modo que o efeito da confiança é maior onde o voto não é obrigatório. No plano individual, de forma coerente com as teorias da confiança política, identificam que a percepção, por parte do eleitor, de que a eleição é injusta, diminui sua propensão a comparecer ao pleito. Por fim, identificam que as redes clientelistas exercem efeito positivo no comparecimento, de modo que o recebimento de benefícios materiais por parte dos eleitores (compra de votos) aumenta sua propensão ao comparecimento. Nesse caso, as máquinas políticas servem como "monitores" do comparecimento (idem, p. 9).

Os argumentos são sintetizados na Tabela 1, a seguir.

Por fim, um balanço que se pode fazer desses estudos, com algumas exceções, como Carreras e Angarita (2013) e Carreras e Irepoglu (2013), é a característica fragmentada: ou se dedicam ao estudo de variáveis macroestruturais (contextos institucional, político e socioeconômico) ou ao nível micro

Tabela 1 - Síntese das variáveis levantadas pela literatura

\begin{tabular}{|c|c|c|}
\hline \multicolumn{3}{|c|}{ Variáveis preditoras } \\
\hline Classificação & $\begin{array}{c}\text { Macro/Contextual } \\
\text { (unidade de análise: os países) }\end{array}$ & $\begin{array}{c}\text { Micro/Individual } \\
\text { (unidade de análise: os indivíduos) }\end{array}$ \\
\hline \multirow{9}{*}{$\begin{array}{l}\text { Aspectos Socioeconômicos da } \\
\text { população }\end{array}$} & Tamanho da população eleitoral & Comportamento \\
\hline & População Urbana & Valores/Crenças \\
\hline & População Rural & Atitudes \\
\hline & Densidade Demográfica & \\
\hline & Produto Interno Bruto per capita & \\
\hline & IDH & \\
\hline & Índice de Gini & \\
\hline & Trabalhadores formais & \\
\hline & Eleitores em idade de voto facultativo & \\
\hline \multirow[t]{6}{*}{ Aspectos do Sistema Eleitoral } & Voto Obrigatório & \\
\hline & $\begin{array}{l}\text { Simultâneidade de eleições } \\
\text { (executivo/Legislativo) }\end{array}$ & \\
\hline & Legislativo Uni/Bicameral & \\
\hline & Tempo oficial de campanha eleitoral & \\
\hline & Existência de reeleição & \\
\hline & Existência de dois turnos & \\
\hline \multirow[t]{5}{*}{ Aspectos conjunturais das eleições } & Tempo de maturidade da democracia & \\
\hline & Desproporcionalidade & \\
\hline & Freedom House & \\
\hline & $\mathrm{N}^{\mathrm{o}}$ efetivo de partidos & \\
\hline & $\mathrm{N}^{\mathrm{o}}$ de candidatos por eleitor & \\
\hline
\end{tabular}

Fonte: Os autores. 


\section{Questões metodológicas}

${ }^{10}$ As bases de dados e informações técnicas podem ser obtidas através do endereço www.latinobarometro.org. Os países são: Argentina, Bolívia, Brasil, Colômbia, Costa Rica, Chile, Equador, El Salvador, Guatemala, Honduras, México, Nicarágua, Panamá, Paraguai, Peru, Uruguai, Venezuela e República Dominicana.

${ }^{11}$ Informações detalhadas sobre a variável dependente e também sobre as independentes são apresentadas no Anexo Metodológico ao final do artigo (Anexo 1).
12 Como mostra o Anexo 3, o percentual de católicos é de mais $70 \%$ na região. (comportamento, atitudes, valores e crenças nutridos pelos indivíduos para com o sistema político). Acreditamos, porém, que para obter um maior potencial explicativo são necessários esforços para analisar as variáveis de níveis diferentes em conjunto, evitando-se o risco de incorrer na falácia ecológica por parte da primeira e de negligenciar o quadro contextual dos países no caso da segunda.

Utilizamos os dados produzidos pela onda de 2009 do Latinobômetro para um conjunto de 18 países latino-americanos ${ }^{10}$. A variável dependente utilizada envolve o comparecimento eleitoral dos cidadãos desses países nas últimas eleições nacionais ${ }^{11}$. Procuramos selecionar como dependentes as medidas que melhor representam os principais fatores apontados pela literatura como relevantes na explicação desse tipo de ação política.

No campo dos atributos individuais a primeira variável incluída foi a idade. Diversos pesquisadores têm apontado que o declínio do comparecimento eleitoral seria maior entre grupos etários mais jovens, revelando uma dimensão geracional do fenômeno (Blais, Gidengil \& Nevitte 2004; Clarke et al., 2004; Dalton 2008; Lyons \& Alexander 2000; Miller \& Shanks 1996; Wass 2007; Wattenberg 2007). Também no nível individual adicionamos o sexo dos entrevistados, com a expectativa de identificar o possível efeito de um componente relacionado à temática do gênero, conforme amplamente documentado nos estudos comparados sobre diversas modalidades de participação política (Verba, Schlozman \& Brady 1995; Schlozman, Burns \& Verba 1994; Ribeiro \& Borba 2010).

Buscando incorporar a hipótese racionalista de que a avaliação produzida pelos indivíduos à dimensão econômica nacional e pessoal impacta as disposições participativas dos cidadãos, incluímos uma variável que procura combinar essas duas dimensões. Também relacionada a esse tema, porém ligada a fatores políticos, incluímos uma variável sobre a avaliação dos entrevistados sobre o funcionamento da democracia em seus respectivos países e outra sobre a confiança depositada nas instituições políticas centrais. Ainda que indiretamente, a percepção dos eleitores sobre a idoneidade do processo eleitoral também diz respeito a esse nível avaliativo do sistema político, sendo incorporada à análise.

A inclusão dessas duas dimensões avaliativas, econômica e política, justifica-se em função da possibilidade de testar a hipótese existente na literatura de que fenômenos como o não comparecimento ou os votos brancos e nulos possam ser expressão do descontentamento do eleitorado (Vitullo 2007; Borba 2008).

Também consideramos pertinente incluir uma medida da adesão dos indivíduos à democracia e outra sobre o seu nível de interesse por política, com o objetivo de testar hipóteses derivadas da tese da cidadania crítica, que associam o refluxo do engajamento cidadão em formas tradicionais de ação política a valores democráticos e à ênfase na auto expressão (Norris 1999; Inglehart \& Welzel 2009).

O orgulho da nacionalidade também consta no modelo proposto como uma proxy do conceito de identidade, associado ao maior ativismo político por certa perspectiva teórica (Melucci 1988; Pizzorno 1966). Também ligada a esse tema, incluímos o atributo católico, entendido como indicador de ligação identitária nas nações latino-americanas predominantemente católicas ${ }^{12}$.

Por fim, adicionamos uma medida ligada à teoria dos recursos, que associa o maior ativismo à existência de recursos materiais e subjetivos, dentre os quais a escolarização aparece com destaque (Verba, Schlozman \& Brady 1995). 
${ }^{13}$ Informações descritivas sobre as variáveis de nível nacional são apresentadas ao final do artigo como Anexo 2.

${ }^{14}$ Informações detalhadas sobre esse indicador podem ser obtidas no endereço www.govindicators.org.
No nível nacional ${ }^{13}$ (ou estrutural), primeiramente adicionamos uma medida da urbanização dos países. Aqui, objetiva-se testar a hipótese, presente em vários autores, de que o comparecimento está relacionado a fatores de natureza ecológica, em especial relacionado aos custos e oportunidades do voto. Nesse sentido, contextos de maior urbanização envolveriam menores custos (de deslocamento, informação etc.) que contextos menos urbanizados (Geys 2006; Lima Júnior 1993; Nicolau 1993). É importante destacar, todavia, a existência de trabalhos que levantam a hipótese alternativa de efeitos negativos da concentração populacional dos grandes centros sobre o comparecimento. HoffmanMartinot (1994), por exemplo, chegou a essa conclusão ao analisar dados a respeito de municipalidades do Reino Unido e da França. Para esse pesquisador, tal efeito seria explicado pela exacerbação do individualismo e pela perda do sentimento de coletividade nesses aglomerados urbanos (idem).

Para verificar a existência de relação entre o nível de desenvolvimento econômico nacional e o comparecimento optamos pela inclusão do PIB per capita. Tal variável tem sido incluída na maioria dos estudos sobre o tema que utilizam dados de contexto (Blais 2006; Nevitte et al., 2000) e se relaciona diretamente às hipóteses derivadas para o nível agregado da teoria do recursos proposta por Verba, Schlozman e Brady (1995). Países com níveis elevados de desenvolvimento econômico tendem a oferecer aos seus cidadãos mais acesso à informação, melhores níveis educacionais, facilidades de transporte, entre outros recursos que se relacionam positivamente com o comparecimento já que reduzem seus custos.

No terreno das configurações institucionais, apontadas pela literatura como importantes determinantes desse tipo de comportamento (Dettrey \& SchwindtBayer 2009; Blais 2006), incluímos o tipo de Legislativo (unicameral ou bicameral), a forma de eleição para o Executivo e Legislativo e a obrigatoriedade do voto. Começando pela obrigatoriedade, apesar das consequências do não comparecimento serem relativamente brandas na maioria dos países (Birch 2009), alguns autores têm apontado efeitos positivos desse mecanismo legal (Gray \& Caul 2000; Franklin 2004). Esperamos, dessa forma, encontrar impacto positivo dessa variável no contexto latino-americano. As demais variáveis institucionais se relacionam à hipótese da complexificação do sistema político e a consequente elevação dos custos de informação para a tomada de decisão por parte do eleitor. Desta forma, nossa expectativa é encontrar maior probabilidade de comparecimento entre eleitores de países em que as características das instituições políticas e do sistema eleitoral facilitem a decisão dos eleitores ao reduzirem a sua complexidade.

Finalmente, ligada à dimensão avaliativa mencionada anteriormente, adicionamos o índice de Efetividade Governamental proposto pelo Banco Mundial, indicador de governança que avalia, no nível nacional, as percepções sobre a qualidade da formulação e implementação dos serviços públicos, o grau de independência da administração em relação a pressões políticas e a credibilidade das organizações governamentais ${ }^{14}$.

Como nossa proposta de análise envolve a combinação de variáveis geradas no nível individual e nacional, optamos por um modelo multinível (ou hierárquico). Uma vez que o comparecimento eleitoral é medido de forma dicotômica (0 e 1), utilizamos um modelo generalizado para variáveis com distribuição de Bernoulli (Raudenbush \& Bryk 2002) ${ }^{15}$.

\section{Os determinantes do comparecimento}

15 O modelo foi estimado com o uso do software HLM 6.08.
Os dados sobre o comparecimento eleitoral entre os países estão sumarizados na Tabela 2, a seguir, revelando percentuais elevados e uma média de 
16 Como já destacado por vários autores, existiria uma tendência de sobrerepresentação do comparecimento eleitoral nas respostas à pesquisas de opinião pública. Tal problema se constitui num limite do presente trabalho, cujas conseqüências analíticas, é bom lembrar, têm sido minimizadas por muitos estudiosos (Rennó et al., 2011).
$75 \%$ na região. É preciso alertar, entretanto, para possíveis divergências entre as respostas fornecidas pelos entrevistados no survey e o seu comparecimento efetivo ${ }^{16}$.

Tabela 2 - Comparecimento eleitoral na América Latina - 2009 (\%)

\begin{tabular}{lc}
\hline País & Comparecimento eleitoral \\
\hline Bolivia & 79.4 \\
Brasil & 81.8 \\
Colombia & 56.2 \\
Costa Rica & 65.5 \\
Chile & 69.8 \\
Ecuador & 87.7 \\
El Salvador & 76.4 \\
Guatemala & 62.1 \\
Honduras & 59.3 \\
México & 69.7 \\
Nicaragua & 73.0 \\
Panamá & 85.0 \\
Paraguay & 71.2 \\
Peru & 84.7 \\
Rep. Dominicana & 73,4 \\
Uruguay & 86.8 \\
Venezuela & 83.0 \\
\hline
\end{tabular}

Fonte: Latinobarómetro (2009).

Para avaliar a magnitude da variação desse comparecimento entre os países, estimamos inicialmente um modelo incondicional, ou seja, sem preditores de nenhum dos dois níveis. Como a variável dependente tem uma distribuição de Bernoulli (comparecimento = 1; não comparecimento $=0$ ), a equação de nível 1 é

$$
\eta_{i j}=\beta_{0 j}
$$

e no nível 2 ,

$$
\beta_{0 j}=\gamma_{00}+\mu_{0 j}
$$

Esse modelo inicial estimou a razão de chance média $\left(\gamma_{00}\right)$ de comparecimento entre os países em 3,169 e a variância entre os países em termos das médias das razões de chance $\left(\tau_{00}\right)$ em 0,270 .

Com base nessa última informação deveríamos calcular o coeficiente de correlação intraclasse (CCI) a partir dessa fórmula

$$
\rho=\frac{\tau_{00}}{\tau_{00}+\sigma^{2}}
$$

Assim, teríamos uma medida da proporção da variação que se deve ao nível dos países. Entretanto, esse cálculo se aplica apenas aos modelos multiníveis lineares. Em modelos não lineares, como os logísticos, a fórmula não é útil porque a variância no nível individual é heterocedástica (Raudenbush \& Bryk 2002, p. 298). Tivemos que recorrer, então, a alternativa proposta por Snijders e 
Bosker (1999), que trata a variável dependente como uma medida contínua latente seguindo uma distribuição logística. A fórmula passa a ser

$$
\rho=\frac{\tau_{00}}{\tau_{00}+\pi^{2} / 3}
$$

em nosso modelo incondicional,

$$
\rho=\frac{0,270}{0,270+\pi^{2} / 3}=\frac{0,270}{0,270+3.29}=0,0758
$$

ou seja, 7,5\% da variação da razão de chance do comparecimento se deve a fatores localizados no nível dos países, o que nos leva a concluir pela estrutura multinível do fenômeno. Como se trata de um comportamento individual era previsível que a maior parte da variação se deva ao nível micro, todavia, 7,5\% de variação no nível nacional não é algo desprezível e merece atenção.

Os resultados do modelo composto pela reunião das variáveis individuais e nacionais apresentadas na seção anterior são consultados na Tabela 3, a seguir.

Os resultados do nosso modelo apontam, em primeiro lugar, que entre as variáveis de contexto, apenas o tipo de eleição para o Executivo (se de turno

\begin{tabular}{|c|c|c|c|}
\hline Variáveis & Coeficiente & Razão de chance & Erro padrão \\
\hline \multicolumn{4}{|l|}{ Nível Individual } \\
\hline Idade & $0.045 * * *$ & 1.046 & 0.008 \\
\hline Sexo & 0.023 & 1.024 & 0.050 \\
\hline Avaliação Econômica (Nacional + Pessoal) & $-0.057 *$ & 0.944 & 0.024 \\
\hline Democratismo & $0.360 * * *$ & 1.433 & 0.074 \\
\hline Orgulho da nacionalidade & $0.168 * *$ & 1.184 & 0.041 \\
\hline Satisfação com a democracia no país & 0.014 & 1.014 & 0.033 \\
\hline Confiança Institucional & -0.033 & 0.967 & 0.016 \\
\hline Interesse por política & $0.183 * * *$ & 1.200 & 0.040 \\
\hline Percepção de que as eleições são limpas & $0.411 * * *$ & 1.501 & 0.085 \\
\hline Católico & $0.191 *$ & 1.210 & 0.064 \\
\hline Escolaridade & $0.039 * * *$ & 1.040 & 0.007 \\
\hline \multicolumn{4}{|l|}{ Nível Nacional } \\
\hline$\%$ de população urbana & $0.098 * * *$ & 1.103 & 0.015 \\
\hline PIB per capita & $-0.179 *$ & 0.836 & 0.010 \\
\hline Tipo de legislativo (Unicameral =0) & $-1.236 * * *$ & 0.290 & 0.210 \\
\hline Tipo de eleição para o executivo ( 1 = 2 turnos $)$ & 0.430 & 1.538 & 0.261 \\
\hline Tipo de eleição para o legislativo ( 1 = misto $)$ & 0.489 & 1.632 & 0.189 \\
\hline Voto obrigatório $(1=\operatorname{sim})$ & $0.780 * *$ & 2.182 & 0.172 \\
\hline Efetividade Governamental (Banco Mundial) & $-0,667 *$ & 0,513 & 0,173 \\
\hline Constante & $-6.919 * * *$ & 0.001 & 0.699 \\
\hline N nível 1 & 15547 & & \\
\hline N nível 2 & 18 & & \\
\hline
\end{tabular}

Tabela 3 - Determinantes individuais e nacionais do comparecimento, América Latina (2009)

Notas: $* * *$ significativo a $0.1 \%, * *$ significativo a $1 \%$ e $*$ Significativo a $5 \%$.

Fonte: Latinobarómetro (2009). 
único ou de dois turnos) e tipo de eleição para o Legislativo (se proporcional de lista vs. misto) não apresentaram significância estatística mínima.

A existência de uma dimensão ecológica para o comparecimento eleitoral se confirma nos dados, já que se verificou que cada aumento percentual da população urbana eleva em mais de $10 \%$ a chance de comparecimento, sendo o efeito acumulado bastante significativo. Os resultados aqui vão de acordo com as expectativas teóricas de que os contextos urbanos diminuem os custos para o comparecimento eleitoral, mas contrariam radicalmente os efeitos negativos da concentração populacional verificados por Geys (2006) em sua meta-análise. A suposta retração do comparecimento em razão do individualismo das grandes cidades, em oposição ao sentimento de coletividade das pequenas cidades (Hoffman-Martinot 1994), não foi aqui confirmada. Os resultados parecem indicar que os efeitos desse suposto individualismo são minimizados pela redução dos custos envolvidos no comparecimento que a concentração nos centros urbanos possibilita, ao menos no contexto latino-americano aqui analisado.

O PIB per capita, por sua vez, apresentou efeito negativo estatisticamente significativo, de modo que cada elevação (medido em milhares de dólares), promove uma redução nas chances de comparecimento em mais de $16 \%$. Aqui também os resultados contrariam a expectativa gerada pela teoria dos recursos tomada na sua versão agregada (Verba, Schlozman \& Brady 1995). Entre os países incluídos na análise, o efeito negativo parece indicar que o desenvolvimento econômico nacional está associado a maior apatia, pelo menos em termos eleitorais, talvez porque a relativa maior satisfação das necessidades materiais reduz a relevância do voto como mecanismo de encaminhamento de demandas. Em um contexto econômico favorável, portanto, a "necessidade" de votar parece ser reduzida.

Passando para as variáveis institucionais, identificamos um efeito bastante significativo da configuração do Legislativo. Na América Latina, o fato de um país ser bicameral reduz a chance de comparecimento eleitoral nas eleições presidenciais em mais de $70 \%$, quando comparados com os unicamerais. Como antecipado acima, acreditamos que esse efeito se explique pela considerável complexidade que o bicameralismo adiciona aos sistemas políticos nacionais e principalmente pelos efeitos dessa complexificação sobre as exigências cognitivas e informacionais inerentes à tomada de decisões por parte dos eleitores.

A efetividade dos governos, medida através do Índice de Efetividade Governamental do Banco Mundial, apresentou um efeito negativo sobre o comparecimento, de modo que cada elevação na escala de efetividade (que vai de -2,5 a 2,5), diminui em quase $50 \%$ as chances de comparecimento eleitoral. A expectativa teórica era inversa aos resultados empíricos encontrados, pois parte da literatura sobre comparecimento interpreta este como produto de contextos com maior previsibilidade e segurança institucional (cujo indicador de efetividade governamental seria uma proxy). O que temos então é que quanto menos efetivo o governo maior o comparecimento eleitoral entre os latino-americanos.

Para finalizar as variáveis institucionais, voto obrigatório apresentou significância estatística e efeitos consideráveis na explicação do comparecimento, de modo que o fato de um país adotar a compulsoriedade eleitoral eleva em mais de $100 \%$ as chances de comparecimento, estendendo para a região latino-americana as conclusões de Gray e Caul (2000) e Franklin (2004) a respeito das democracias com longo histórico democrático.

Passando para as variáveis de nível individual, verificamos, em primeiro lugar, que as variáveis sexo, satisfação com a democracia e confiança nas instituições, não se mostraram estatisticamente significativas. 
Entre as demais, verificamos que idade exerceu efeito positivo, de modo que cada ano de vida aumenta em mais de $4 \%$ as chances de comparecimento. Tal dado evidencia também, para os países da América Latina, o fenômeno do declínio do envolvimento dos jovens para com a política eleitoral, fenômeno este que tem sido também identificado em outros contextos (Dalton 2008).

A variável escolaridade, utilizada aqui como proxy de recurso individual, também apresentou efeito positivo, com cada ano de estudo elevando em $4 \%$ as chances de comparecimento eleitoral. Considerando que esta é uma escala que vai de 0 a 15, o efeito acumulado de escolaridade é bastante significativo. Esse resultado mais uma vez confirma a relevância da escolaridade como principal componente da dimensão dos recursos, tão destacado pelo já mencionado estudo de Verba, Schlozman e Brady (1995) e também em estudos sobre diferentes comportamentos participativos no contexto dos países latino-americanos (Borba \& Ribeiro 2010; Ribeiro \& Borba 2011).

Avaliação da economia (nacional e pessoal) apresentou efeito negativo sobre comparecimento, de modo que cada elevação na escala de avaliação provoca um declínio de mais de 5\% nas chances de um cidadão latino-americano ter comparecido para votar. $\mathrm{O}$ voto parece estar ligeiramente associado à posturas descontentes com a dimensão econômica nacional e pessoal.

Já a variável democratismo, que representa o posicionamento de que a democracia é preferível a qualquer outra forma de governo, eleva em mais de $40 \%$ as chances de comparecimento, da mesma forma que ter interesse por política eleva em mais de $20 \%$. Esse resultado contraria a expectativa gerada pelas teorias da cidadania crítica propostas por autores como Norris (1999) e Inglehart e Welzel (2009). Como indicamos anteriormente, para esses pesquisadores uma postura crítica em relação às modalidades tradicionais de participação política ligadas à representação, como o voto, estaria associada a maior democratismo. Na verdade, tanto a cidadania crítica como o democratismo seriam componentes do que Inglehart tem chamado a várias décadas de síndrome de valores pós-materialistas (Inglehart 1990; 2001).

Outra variável atitudinal que exerceu efeito positivo sobre comparecimento foi a percepção de que as eleições são limpas, elevando em mais de $50 \%$ as chances de participação eleitoral. Como o comparecimento demanda o investimento de recursos, ainda que em alguns casos se reduza ao tempo de deslocamento até os locais de votação, a percepção de que o processo eleitoral é idôneo parece ser uma informação relevante no cálculo do eleitor sobre a pertinência de tal investimento.

Orgulho de nacionalidade eleva em $18 \%$ tais chances. A opção religiosa pelo catolicismo, que constitui outro indicador de identidade também eleva em mais de $20 \%$ tais chances.

\section{Conclusões}

Considerando o conjunto de testes realizados e interpretados acima, o que pode-se perceber é que o comparecimento eleitoral na América Latina é influenciado tanto por características do contexto (político-institucionais e econômicas), quanto por dimensões propriamente individuais (valores, crenças, atributos sócios demográficos). Entre as características de contexto, o estudo confirma dimensões já amplamente relatadas pela literatura, entre elas o forte efeito positivo da compulsoriedade do voto e dos sistemas unicamerais sobre o comparecimento. 
Por outro lado, há uma novidade em relação à literatura: o fato de que o comparecimento é maior em contextos de baixa efetividade governamental e de menor PIB per capita.

A inclusão das variáveis individuais mostrou que quem mais faz uso do voto são aqueles com maior escolaridade, mais idade, integrados socialmente à comunidade nacional (em termos de religião dominante e do sentimento de orgulho pelo país), que acreditam na lisura do sistema político (que as eleições são limpas) e que são portadores de uma adesão normativa à democracia. Tais características fazem parte daqueles que seriam os atributos típicos de um "bom cidadão", na forma como teorizado por alguns autores (Dalton 2008; Van Deth 2009). O que não esperávamos era o efeito positivo da insatisfação econômica sobre o comparecimento, uma constatação sem precedentes na literatura.

Dessa forma, o que os dados parecem indicar é que o comparecimento eleitoral na América Latina seja a "voz" dos cidadãos portadores de maiores recursos, que valorizam a democracia e suas instituições, mas que estão insatisfeitos com a economia e que vivem em contextos de baixa efetividade governamental.

Ednaldo Aparecido Ribeiro (ednaldorip@uol.com.br) é Doutor em Sociologia pela Universidade Federal do Paraná (UFPR) e Professor da Universidade Estadual de Maringá (UEM).

Julian Borba (borbajulian@yahoo.com.br) é Doutor em Ciência Política pela Universidade Federaldo Rio Grande do Sul (UFRGS) e Professor da Universidade Federal de Santa Catarina (UFSC)

Rafael da Silva (eu_fael@yahoo.com.br) é Doutorando em Sociologia Política pela Universidade Federal de Santa Catarina (UFSC) e professor da Universidade Estadual de Maringá (UEM).

\section{Referências}

Blais, A.; Gidengil, E.; Nevitte, N. 2004. Where does Turnout Decline come from? European Journal of Political Research, 43 , pp. 221-236.

2006. What affects Voter Turnout? Annual Review of Political Science, 9, pp. 111-125.

Borba, J. 2008. As bases sociais e atitudinais da alienação eleitoral no Brasil. Revista Debates, 2, pp. 134-157.

Birch, S. 2009. Full Participation: A Comparative Study of Compulsory Voting. Manchester: Manchester University Press.

Carreras, M.; Angarita, N.C. 2013. Who Votes in Latin America? A Test of Three Theoretical Perspectives. Comparative Political Studies, 47(8), pp. 1079-1104.

Carreras, M.; Irepoglu, Y. 2013. Trust in Elections, Vote Buying, and Turnout in Latin America. Electoral Studies, 32(4), pp. 609-619.

Clarke, H.; Sanders, D.; Stewart, M.C.; Whiteley, P. 2004. Political Choice in Britain. Oxford: Oxford University Press.

Dalton, R.J. 2008. The Good Citizen. How a Younger Generation is Reshaping American Politics. Washington, D.C.: CQ Press.

Denny, D.; Doyle, O. Political Interest, Cognitive Ability and Personality: Determinants of Voter Turnout in Britain. British Journal of Political Science, 38(2), pp. 291-310.

Dettrey, B.; Schwindt-Bayer, L. 2009. Voter Turnout in Presidential Democracies. Comparative Political Studies, 42(10), pp. 1317-1338.

Fornos, A.C.; Power, T.; Garand, J. 2004. Explaining Voter Turnout in Latin America, 1980 to 2000. Comparative Political Studies, 37(8), pp. 909-940.

Franklin, M. 2004. Voter Turnout and the Dynamics of Electoral Competition in Established Democracies since 1945. Cambridge, MA: Cambridge University Press.

Gallego, A. 2010. Undestanding Unequal Turnout? Education and Voting in Comparative Perspective. Electoral Studies, 29(2), pp. 238-248.

Geys, B. 2006. Explaining Voter Turnout: A Review of Aggregate-Level Research. Electoral Studies, 25, pp. 637-663.

Gray, M.; Caul, M. Declining Voter Turnout in Advanced Industrial Democracies, 1950 to 1997. The Effects of Declining Group Mobilization. Comparative Political Studies, 33(9), pp. 1091-1122.

Hoffman-Martinot, V. 1994. Voter Turnout in French Municipal Elections. In: L. Lopez-Nieto, ed. Local Elections in Europe. Barcelona: Institut deciènciespolitiques I socials.

Huntington, S. 1994. A terceira onda:a democratização no final do século XX. São Paulo: Ática.

Inglehart, R. 1990. Culture Shift in Advanced Industrial Society. Princeton: Princeton University Press. . 1991. Modernización y posmodernización: el cambio cultural, económico y político en 43 sociedades. Madrid: Centro de Investigaciones Sociológicas. 
Inglehart, R.; Welzel, C. 2009. Modernização, mudança cultural e democracia: a sequência do desenvolvimento humano. São Paulo: Francis.

Lima Júnior, O.B. 1993. Democracia e instituições políticas no Brasil dos anos 80. São Paulo: Loyola.

Lyons, W.; Alexander, R. 2000. A Tale of Two Electorates: Generational Replacement and the Decline of Voting in Presidential Elections. Journal of Politics, 62(4), pp. 1014-1034.

Melucci, A. 1988. Getting Involved: Identity and Mobilization in Social Movements. In: B. Klandermans; H. Kriesi; S. Tarrow, eds. International Social Movement Research: from Structure to Action. Comparing Social Movement Research across Cultures. Greenwich: Jai Press.

Miller, W.E.; Shanks, J.M. 1996. The New American Voter. Cambridge, MA: Harvard University Press.

Nevitte, N.; Blais, A.; Gidengil, E.; Nadeau, R. 2000. Unsteady State: The 1997 Canadian Federal Election. Don Mills: Oxford University Press.

Nicolau, J. 2003. A participação eleitoral no Brasil. In: L.W. Viana, ed. A democracia e os três poderes no Brasil. Belo Horizonte: Editora UFMG.

Norris, P. 1999. Critical Citizens: Global Support for Democratic Governance. Oxford: Oxford University Press.

O’Donnell, G.; Schimitter, P.C. 1986. Transitions from Authoritarian Rule. Baltimore: John Hopkins University Press.

Pizzorno, A. 1966. Condizioni della participazione politica. In:___. Le radici della politica assoluta. Feltrinelli: Milano.

Power, T.J. 2009. Compulsory for Whom? Mandatory Voting and Electoral Participation in Brazil, 1986-2006. Journal of Politics in Latin America, 1(1), pp. 97-122.

Raudenbush, S.W.; Bryk, A.S. 2002. Hierarchical Linear Models. Applications and Data Analysis Methods. New York: Sage.

Rennó, L.; Smith, A.E.; Layton, M.L.; Batista, F. 2011. Legitimidade e qualidade da democracia no Brasil: uma visão da cidadania. São Paulo: Intermeios.

Ribeiro, E.; Borba, J. 2010. Participação e pós-materialismo na América Latina. Revista Opinião Pública, 16(1), pp. 28-63. . 2011. As dimensões da participação política no Brasil. Teoria \& Pesquisa, 20, pp. 11-36.

Schlozman, K.L.; Burns, N.; Verba, S. 1994. Gender and the Pathways to Participation: The Role of Resources. The Journal of Politics, 56(4), pp. 963-990.

Snijders, T.; Bosker, R. 1999. Multilevel Analysis: An Introduction to Basic and Advanced Multilevel Modeling. Thousand Oaks: Sage Publications.

Van Deth, J. 2009. The 'Good European Citizen': Congruence and Consequences of Different Points of View. European Political Science, 8, pp. 175-189.

Verba, S.; Schlozman, K.L.; Brady, H.E. 1995. Voice and Equality. Civic Voluntarism in American Politics. Cambridge, MA: Harvard University Press.

Vitullo, G. 2007. Teorias da Democratização e Democracia na Argentina. Porto Alegre: Sulina.

Wass, H. 2007. The Effects of Age, Generation, and Period on Turnout in Finland, 1975-2003. Electoral Studies, 26, pp. 648-659.

Wattenberg, M.P. 2007. Is Voting for Young People? New York: Pearson Longman.

\section{Outras fontes}

Latinobarómetro. 2009. Opinion Pública Latinoamericana. Disponível em http://www.latinobarometro.org/ Acesso em 25.abr. 2015

International Institute for Democracy and Electoral Assistance. 2009. Databases and Networks. Disponível em: http://www.idea.int/resources/databases.cfm. Acesso em: 25.abr. 2015. 


\section{Abstract}

Because of its centrality in the democratic system, the voter participation is privileged object of many political scientists. In general, the studies focus on the reality of developed countries, addressing, among other topics, the turnout and its determinants. There are few studies that address, or at least consistently, the third wave of democratic regimes, especially the Latin American countries. Looking to contribute to fill this gap, this paper sought to map the determinants of voter turnout in Latin America, breaking the dichotomy macro vs. micro, integrating them into a single analytical model. We use data from Latinobarometer in its 2009 round, which extract variables on the micro level (individual) and a database with macro information about countries where voter live. These late measures summarize the situation of country's economy, characteristics of their electoral systems and the situation of political and individual freedoms among others. The data were combined in multilevel logistic regression model using the HLM 6.8 software. The ecological dimension appears as important, with the increase in urban population implies increased chances of voter attend, while GDP growth implies a reduction in the probability. From the point of view of the legislative setting, be bicameral reduces the chances of voter turnout at the polls. Moreover, the compulsory voting significantly increases the turnout. As for the individual variables, the increase in years of life is accompanied by an increase in electoral participation, as in the case of education. Likewise, be in favor of democracy promotes the propensity to participate in the election as well as consider that elections occur cleanly and transparently. The article contributes to the debate by focusing on the Latin American elections, since such studies have been conducted only in stablished democracy. Its relevance is further enhanced due to the identification of some major differences in the results usually found in these contexts with long democratic tradition, as the negative effects of GDP and government effectiveness. Finally, the data indicate that the voter turnout in the LA is the voice of citizens with greater resources who value democracy and its institutions, but are dissatisfied with the economy and living in contexts of limited effectiveness in the performance of government.

KEYWORDS: vote turnout; structural constraints; individual determinants; multilevel analysis; Latin America.

License information: This is an open-access article distributed under the terms of the Creative Commons Attribution License, which permits unrestricted use, distribution, and reproduction in any medium, provided the original work is properly cited. 


\section{Anexos 1 - Anexo Metodológico}

Tabela 1A - Informações técnicas das variáveis

\begin{tabular}{|c|c|c|c|}
\hline Variável & Questão & Codificação & Detalhamento da variável \\
\hline \multicolumn{4}{|c|}{ Variáveis de nível individual extraídas do Latinobarómetro 2009} \\
\hline \multirow[t]{2}{*}{$\begin{array}{l}\text { 1. Comparecimento } \\
\text { eleitoral }\end{array}$} & \multirow[t]{2}{*}{$\begin{array}{l}\text { ¿Con respecto a la última elección } \\
\text { presidencial que hizoUd.? }\end{array}$} & 0 = Não compareceu & \multirow{3}{*}{$\begin{array}{l}\text { Para obter as codificações ori- } \\
\text { ginais consultar o Relatório do } \\
\text { Latinobarômetro, disponível em } \\
\text { http://www.latinobarometro.org }\end{array}$} \\
\hline & & 1 = Compareceu & \\
\hline 2. Idade & ¿Cuál es sue dad? & $\begin{array}{l}\text { aberta com unidade }= \\
\text { anos de vida }\end{array}$ & \\
\hline \multirow[t]{2}{*}{ 3. Sexo } & \multirow[t]{2}{*}{-} & $0=$ feminino & \multirow{2}{*}{$\begin{array}{l}\text { Variável com valores de } 0 \text { a } 8 \text {, } \\
\text { produzida pela combinação de } \\
\text { duas questões: }\end{array}$} \\
\hline & & $1=$ masculino & \\
\hline \multirow{5}{*}{$\begin{array}{l}\text { 4. Avaliação } \\
\text { econômica }\end{array}$} & \multirow{2}{*}{$\begin{array}{l}\text { 1)¿Cómo calificaria en general la situa- } \\
\text { ción económica actual del país? }\end{array}$} & $0=$ péssima & \multirow{2}{*}{$\begin{array}{l}\text { 1) Avaliação da situação econô- } \\
\text { mica nacional }\end{array}$} \\
\hline & & $1=$ ruim & \\
\hline & \multirow{3}{*}{$\begin{array}{l}\text { 2)¿Cómo calificaria en general su } \\
\text { situacion económica actual y la de su } \\
\text { família? }\end{array}$} & $2=$ regular & \multirow{3}{*}{$\begin{array}{l}\text { 2) Avaliação da situação econô- } \\
\text { mica pessoal e familiar. }\end{array}$} \\
\hline & & $3=$ boa & \\
\hline & & 4 = ótima & \\
\hline \multirow[t]{2}{*}{ 5. Democratismo } & \multirow[t]{2}{*}{$\begin{array}{l}\text { ¿Com cuál de as seguientes frases está } \\
\text { Ud. más de acuerdo? }\end{array}$} & $\begin{array}{l}0=\text { en algunas } \\
\text { circunstancias.../a la } \\
\text { gente como uno... }\end{array}$ & \\
\hline & & $\begin{array}{l}1=\text { la democracia es } \\
\text { preferible.. }\end{array}$ & \\
\hline \multirow{4}{*}{$\begin{array}{l}\text { 6. Orgulho da } \\
\text { nacionalidade }\end{array}$} & \multirow{4}{*}{$\begin{array}{l}\text { ¿Cuán orgulloso está Ud. de ser } \\
\text { (nacionalidade)? }\end{array}$} & $0=$ nada orgulhoso & \\
\hline & & $1=$ pouco orgulhoso & \\
\hline & & $2=$ bastante orgulhoso & \\
\hline & & $3=$ muito orgulhoso & \\
\hline \multirow{4}{*}{$\begin{array}{l}\text { 7.Satisfação com a } \\
\text { democracia no país }\end{array}$} & \multirow{4}{*}{$\begin{array}{l}\text { ¿En general, diria Ud. que está muy } \\
\text { satisfecho, más bien satisfecho, no muy } \\
\text { satisfecho o nada satisfecho con el } \\
\text { funcionamento de la democracia en } \\
\text { (país)? }\end{array}$} & $0=$ nada satisfeito & \\
\hline & & 1 = não muito satisfeito & \\
\hline & & $2=$ satisfeito & \\
\hline & & $3=$ muito satisfeito & \\
\hline \multirow[t]{4}{*}{$\begin{array}{l}\text { 8. Confiança } \\
\text { institucional }\end{array}$} & \multirow{4}{*}{$\begin{array}{l}\text { Por favor, mire esta tarjeta y digame, } \\
\text { para cada uno de los grupos, institu- } \\
\text { ciones o personas mencionadas en la } \\
\text { lista cuánta confianza tiene usted en } \\
\text { ellas: mucha, algo, poca o ninguma. }\end{array}$} & $0=$ nenhuma & $\begin{array}{l}\text { Variável com valores de } 0 \text { a } 9 \text {, } \\
\text { produzida pela combinação de } \\
\text { três questões: }\end{array}$ \\
\hline & & $1=$ pouca & 1) Confiança no Governo \\
\hline & & $2=$ alguma & 2) Confiança no Congresso \\
\hline & & $3=$ muita & 3) Confiança nos Partidos \\
\hline \multirow{4}{*}{$\begin{array}{l}\text { 9.Interesse por } \\
\text { política }\end{array}$} & \multirow{4}{*}{$\begin{array}{l}\text { ¿Cuán interessado está Ud. Enla } \\
\text { política? }\end{array}$} & $0=$ nada interessado & \\
\hline & & $1=$ pouco interessado & \\
\hline & & $2=$ interessado & \\
\hline & & $3=$ muito interesado & \\
\hline \multirow{2}{*}{$\begin{array}{l}\text { 10. Percepção de } \\
\text { que as eleições são } \\
\text { limpas }\end{array}$} & \multirow{2}{*}{$\begin{array}{l}\text { ¿Cree Ud., en términos generales, que } \\
\text { las elecciones em este país son limpias o } \\
\text { son fraudulentas? }\end{array}$} & $0=$ fraudulentas & \\
\hline & & $1=$ limpas & \\
\hline \multirow[t]{2}{*}{ 11. Católico } & \multirow[t]{2}{*}{ ¿Cuál es su religión? } & 0 = não católico & \\
\hline & & 1 = católico & \\
\hline 12. Escolaridade & $\begin{array}{l}\text { ¿Qué estúdios há realizado? ¿Cuál es el } \\
\text { último año cursado? }\end{array}$ & $0=$ não respondeu & \\
\hline
\end{tabular}




\begin{tabular}{|c|c|c|c|}
\hline Variável & Questão & Codificação & Detalhamento da variável \\
\hline & & $\begin{array}{l}1=\text { sem estudos for- } \\
\text { mais }\end{array}$ & \\
\hline & & $2=1$ ano & \\
\hline & & $3=2$ anos & \\
\hline & & {$[\ldots]$} & \\
\hline & & $13=12$ anos & \\
\hline & & $\begin{array}{l}14 \text { = universitário } \\
\text { incompleto }\end{array}$ & \\
\hline & & $\begin{array}{l}15 \text { = universitário } \\
\text { completo }\end{array}$ & \\
\hline \multicolumn{4}{|c|}{ Variáveis de nível nacional } \\
\hline $\begin{array}{l}\text { 13. Percentual de } \\
\text { população urbana }\end{array}$ & & $\begin{array}{l}\text { Codificação: \% de ha- } \\
\text { bitantes em áreas urba- } \\
\text { nas }\end{array}$ & $\begin{array}{l}\text { Fonte: Banco Mundial - Data } \\
\text { Bank } 2009\end{array}$ \\
\hline 14. PIB per capita & & $\begin{array}{l}\text { Codificação: produto } \\
\text { interno bruto, conver- } \\
\text { tido em dólares ameri- } \\
\text { canos usando o método } \\
\text { Atlas do Banco Mun- } \\
\text { dial, dividido pela po- } \\
\text { pulação do meio do } \\
\text { ano. }\end{array}$ & $\begin{array}{l}\text { Fonte: Banco Mundial - Data } \\
\text { Bank } 2009\end{array}$ \\
\hline \multirow[t]{2}{*}{$\begin{array}{l}\text { 15. Tipo de } \\
\text { legislativo }\end{array}$} & & $0=$ unicameral & $\begin{array}{l}\text { Fonte: Laboratório de Estudos } \\
\text { Experimentais - LEEX - } 2009\end{array}$ \\
\hline & & $1=$ bicameral & \\
\hline \multirow[t]{2}{*}{$\begin{array}{l}\text { 16. Tipo de eleição } \\
\text { para o executivo }\end{array}$} & & $0=$ um turno & $\begin{array}{l}\text { Fonte: International Institute for } \\
\text { Democracy and Electoral Assis- } \\
\text { tance - } 2009\end{array}$ \\
\hline & & $1=$ dois turnos & \\
\hline \multirow[t]{2}{*}{$\begin{array}{l}\text { 17. Tipo de eleição } \\
\text { para o legislative }\end{array}$} & & $\begin{array}{l}0=\text { proporcional de } \\
\text { lista }\end{array}$ & $\begin{array}{l}\text { Fonte: International Institute for } \\
\text { Democracy and Electoral Assis- } \\
\text { tance - } 2009\end{array}$ \\
\hline & & $1=$ misto & \\
\hline \multirow[t]{2}{*}{$\begin{array}{l}\text { 18. Voto } \\
\text { obrigatório }\end{array}$} & & $0=$ facultativo & $\begin{array}{l}\text { Fonte: International Institute for } \\
\text { Democracy and Electoral Assis- } \\
\text { tance - } 2009\end{array}$ \\
\hline & & 1 = obrigatório & \\
\hline $\begin{array}{l}\text { 19. Efetividade } \\
\text { Governamental }\end{array}$ & & $\begin{array}{l}\text { escala com valores en- } \\
\text { tre }-2,5 \text { a } 2,5\end{array}$ & Fonte: Banco Mundial - 2009 \\
\hline
\end{tabular}

Fonte: elaboração própria. 


\section{Anexo 2}

Tabela 1B - Estatísticas descritivas das variáveis nacionais por país

\begin{tabular}{|c|c|c|c|c|c|c|c|}
\hline País & $\begin{array}{l}\text { \% Pop. } \\
\text { Urbana }\end{array}$ & $\begin{array}{l}\text { PIB Per } \\
\text { capita }\end{array}$ & Legislativo & $\begin{array}{c}\text { Eleição } \\
\text { executivo }\end{array}$ & $\begin{array}{c}\text { Eleição } \\
\text { legislativo }\end{array}$ & $\begin{array}{c}\text { Voto } \\
\text { obrigatório }\end{array}$ & $\begin{array}{l}\text { Efetivid. } \\
\text { Govern. }\end{array}$ \\
\hline Argentina & 92 & 9,124 & Bicameral & Dois turnos & $\begin{array}{c}\text { Proporc.de } \\
\text { lista }\end{array}$ & Sim & $-0,420$ \\
\hline Bolívia & 67 & 1,979 & Bicameral & Dois turnos & Misto & Sim & $-0,720$ \\
\hline Brasil & 87 & 10,710 & Bicameral & Dois turnos & $\begin{array}{l}\text { Proporci. de } \\
\text { lista }\end{array}$ & Sim & 0,076 \\
\hline Chile & 89 & 12,431 & Bicameral & Dois turnos & $\begin{array}{l}\text { Proporc. de } \\
\text { lista }\end{array}$ & Sim & 1,209 \\
\hline Colômbia & 75 & 6,240 & Bicameral & $\begin{array}{c}\text { Proporci. de } \\
\text { lista }\end{array}$ & Não & 0,041 & \\
\hline Costa Rica & 64 & 7,691 & Unicameral & $\begin{array}{c}\text { Proporc. de } \\
\text { lista }\end{array}$ & Sim & 0,431 & \\
\hline El Salvador & 61 & 3,426 & Unicameral & $\begin{array}{c}\text { Proporc. de } \\
\text { lista }\end{array}$ & Não & $-0,040$ & \\
\hline Equador & 67 & 4,008 & Unicameral & $\begin{array}{c}\text { Proporc. de } \\
\text { lista }\end{array}$ & Sim & $-0,840$ & \\
\hline Guatemala & 50 & 2,862 & Unicameral & $\begin{array}{c}\text { Proporc. de } \\
\text { lista }\end{array}$ & Sim & $-0,690$ & \\
\hline Honduras & 49 & 2,026 & Unicameral & Um turno & $\begin{array}{c}\text { Proporc. de } \\
\text { lista }\end{array}$ & Sim & $-0,710$ \\
\hline México & 78 & 9,133 & Bicameral & Misto & Sim & 0,168 & \\
\hline Nicarágua & 57 & 1,132 & Unicameral & $\begin{array}{l}\text { Proporc. de } \\
\text { lista }\end{array}$ & Não & $-1,040$ & \\
\hline Panamá & 75 & 7,589 & Unicameral & Um turno & Misto & Sim & 0,246 \\
\hline Paraguai & 62 & 2,840 & Bicameral & $\begin{array}{l}\text { Proporc. de } \\
\text { lista }\end{array}$ & Sim & $-0,930$ & \\
\hline Peru & 72 & 5,401 & Unicameral & $\begin{array}{c}\text { Proporc. de } \\
\text { lista }\end{array}$ & Sim & $-0,360$ & \\
\hline República Dominicana & 71 & 5,215 & Bicameral & $\begin{array}{c}\text { Proporc. de } \\
\text { lista }\end{array}$ & Sim & $-0,440$ & \\
\hline Uruguai & 93 & 11,633 & Bicameral & $\begin{array}{l}\text { Proporc.de } \\
\quad \text { lista }\end{array}$ & Sim & 0,668 & \\
\hline Venezuela & 94 & 13,590 & Bicameral & Um turno & Misto & Não & $-0,950$ \\
\hline
\end{tabular}

Fonte: International Institute for Democracy and Electoral Assistance (2009). 


\section{Anexo 3}

Tabela 1C - Estatísticas descritivas das variáveis

\begin{tabular}{|c|c|c|c|c|c|}
\hline Nome & $\mathbf{N}$ & Méd. & Desv. & Mín. & Máx. \\
\hline Comparecimento eleitoral & 19882 & 0,75 & 0,43 & 0,00 & 1,00 \\
\hline Idade & 20204 & 40,33 & 16,57 & 16 & 98 \\
\hline Sexo & 20204 & 0,48 & 0,50 & 0,00 & 1,00 \\
\hline Avaliação Econômica & 19991 & 3,68 & 1,46 & 0,00 & 8,00 \\
\hline Democratismo & 18735 & 0,64 & 0,48 & 0,00 & 1,00 \\
\hline Orgulho da nacionalidade & 20017 & 2,54 & 0,72 & 0,00 & 3,00 \\
\hline Satisfação com a democracia no país & 19318 & 1,46 & 0,90 & 0,00 & 3,00 \\
\hline Confiança Institucional & 19086 & 3,45 & 2,23 & 0,00 & 9,00 \\
\hline Interesse por política & 19969 & 1,02 & 0,96 & 0,00 & 3,00 \\
\hline Percepção de que as eleições são limpas & 18216 & 0,49 & 0,50 & 0,00 & 1,00 \\
\hline Católico & 20020 & 0,71 & 0,45 & 0,00 & 1,00 \\
\hline Escolaridade & 20204 & 3,72 & 1,74 & 1,00 & 17,00 \\
\hline$\%$ de população urbana & 18 & 72,39 & 14,28 & 49,00 & 94,00 \\
\hline PIB per capita & 18 & 6501,67 & 3913,98 & 1132,00 & 13590,00 \\
\hline Tipo de legislativo & 18 & 0,56 & 0,51 & 0,00 & 1,00 \\
\hline Tipo de eleição para o executivo & 18 & 0,83 & 0,38 & 0,00 & 1,00 \\
\hline Tipo de eleição para o legislativo & 18 & 0,22 & 0,43 & 0,00 & 1,00 \\
\hline Voto obrigatório & 18 & 0,78 & 0,43 & 0,00 & 1,00 \\
\hline Efetividade Governamental & 18 & $-0,24$ & 0,63 & $-1,04$ & 1,21 \\
\hline
\end{tabular}

Fonte: Latinobarómetro (2009) e International Institute for Democracy and Electoral Assistance (2009). 